\title{
Ion Transport in Glass-Forming Calcium Potassium Nitrate: From Complex Behaviours to Unexpected Simplicities
}

\author{
Klaus Funke ${ }^{1, a^{*}}$, Radha D. Banhatti ${ }^{2, b}$ and Malcolm D. Ingram ${ }^{3, c}$ \\ ${ }^{1}$ Institute of Physical Chemistry, University of Muenster, Corrensstrasse 28-30, 48149 Muenster, \\ Germany \\ ${ }^{2}$ Division of Materials Chemistry, Ruđer Bošković Institute, Bijenička cesta 54, 10000 Zagreb, \\ Croatia \\ ${ }^{3}$ University of Aberdeen, Department of Chemistry, The School of Natural and Computing \\ Sciences, Aberdeen AB24 3UE, Scotland, United Kingdom \\ ak.funke@uni-muenster.de, brbanhatt@irb.hr, cm.d.ingram@abdn.ac.uk
}

\begin{abstract}
Keywords: ion transport, fragile melts, molten CKN, glass transition, coupled/decoupled transition, MIGRATION concept, elementary and successful displacements, activation energies and volumes, activation moduli, high-frequency shear modulus, glass/melt continuities
\end{abstract}

\begin{abstract}
Re-examination of published conductivity spectra for $2 \mathrm{Ca}\left(\mathrm{NO}_{3}\right)_{2} \cdot 3 \mathrm{KNO}_{3}(\mathrm{CKN})$ in its molten and glassy states, in terms of the MIGRATION concept, has brought to light new links between elementary processes occurring within one picosecond and their successful outcomes, i.e. those which determine the DC conductivities. The starting point of this analysis is the transition at $378 \mathrm{~K}$, which arises from a change from a decoupled to a coupled transport mechanism. Remarkably, while there is a change in the shape of the conductivity dispersion and a jump in its onset frequency, there is no change in the temperature dependence of DC conductivity. What emerges from the analysis is a surprising continuity in high-frequency behaviour, with the activation energy and volume for elementary displacements, $E_{\text {ed }}$ and $\mathrm{V}_{\text {ed }}$, remaining constant from $300 \mathrm{~K}$ in the glass up to $500 \mathrm{~K}$ in the melt. The ratio, $\mathrm{E}_{\mathrm{ed}} / \mathrm{V}_{\mathrm{ed}}$, turns out to be equal to our previously defined DC activation moduli for $\mathrm{CKN}$, given by $\mathrm{E}_{\mathrm{DC}}(\mathrm{T}) / \mathrm{V}_{\mathrm{DC}}(\mathrm{T})$ and $\mathrm{T}_{\mathrm{g}} /(\mathrm{dT} / \mathrm{dp})$ for charge transport in the melt and structural relaxation at $\mathrm{T}_{\mathrm{g}}$, respectively. It seems that, at very short times, molten $\mathrm{CKN}$ behaves just like an elastic solid. The importance of elastic forces for ionic transport in $\mathrm{CKN}$ is corroborated by the finding that the published value of the high-frequency shear modulus of glassy $\mathrm{CKN}_{\infty}, \mathrm{G}_{\infty}$, matches those of $\mathrm{E}_{\text {ed }} / \mathrm{V}_{\text {ed }}$ and hence of both activation moduli. The detected continuity in the picosecond behaviour of $\mathrm{CKN}$ across the glass transition could provide a new link between fragile liquids and glassy materials in general.
\end{abstract}

\section{Introduction and a Brief Preview}

Glass-forming melts in the system calcium nitrate - potassium nitrate $(\mathrm{CKN})$ have been the subject of numerous studies since the 1960s and are still attracting interest. They combine relatively complex patterns of behaviour with apparent structural simplicity, and illustrate many paradigms of molten salt and glassy behaviour. It was Angell [1] who first drew attention to their adherence to the VogelTammann-Fulcher (VTF) relation [2-4], and linked the $\mathrm{T}_{0}$ parameter of that approach to the possibility of producing a glass of very low residual entropy [5]. However, it soon became apparent that a very different pattern of behaviour emerges at temperatures some $40 \mathrm{~K}$ above the glasstransition [6,7]. Ion mobilities now follow the Arrhenius law, and on cooling, glasses are obtained with well-defined potassium-ion conductivities. While some computer simulations have focused on the motion of the nitrate ions in order to account for liquid-like properties in the melt [8], others have focused on the mobility of potassium ions in the glassy state [9]. Clear evidence also emerges from neutron and x-ray scattering data and from reverse Monte Carlo modelling of strong intermediate range ordering and the presence of chainlike substructures containing $\mathrm{Ca}^{2+}$ and $\mathrm{NO}_{3}{ }^{-}$ions [10]. 
Despite these structural and behavioural complexities, CKN is often considered to be representative of the class of fragile liquids, see e.g. Refs. 11 and 12, and it has been the subject of many detailed investigations. For example, there have been several attempts to interpret the behaviour of the melt in its approach to the glass transition in terms of mode-coupling theory (MCT) [13]. However, there are still differing opinions about whether the appropriate critical temperature, $\mathrm{T}_{\mathrm{C}}$, has been successfully identified and indeed where to expect it [14-16]. There has also been significant interest over the years in the effects of pressure on the conductivity, based initially on the experiments of Angell, Pollard and Strauss [17]. Subsequent 'master-plots' showed how the variable activation energies for conductivity characteristic of the VTF region of behaviour are directly proportional to the corresponding activation volumes, revealing a close link between the behaviour of molten CKN and liquid polymer electrolytes [18, 19]. Remarkably, these ion-transport related properties of the melt are also linked to the effects of pressure on the glass transition temperature [19-21]. The question arises as what is the underlying reason for these emerging links between molten and glassy behaviour, and hence between ion transport and structural relaxation.

There have been numerous publications relating to the ion dynamics in CKN. For the interpretation of their frequency-dependent electric and dielectric data some authors have preferred the electricmodulus representation, see Refs. 7 and 22, while others have based their discussion on AC permittivities [23] and AC conductivities [24, 25]. In Section 2 of this paper, we present a novel analysis (building on the MIGRATION concept formalism [26-28]) of our previously published conductivity spectra of glassy and molten CKN [25, 29, 30].

Our DC conductivity data of CKN, of composition $2 \mathrm{Ca}\left(\mathrm{NO}_{3}\right)_{2} \cdot 3 \mathrm{KNO}_{3}$, see Fig. 1 , are in perfect agreement with those published much earlier (in 1970) by Bose, Weiler and Macedo [6] and again by Howell, Bose, Macedo and Moynihan in 1974 [7]. Likewise, our AC conductivity spectra, see the following Section, agree well with those of Howell et al. [7], although extending to much higher frequencies and higher temperatures. Notably, however, there is a basic difference between the analysis given by Howell et al. (in terms of a distribution of relaxation times) and the one adopted in our present paper, which employs linear response theory, as introduced by Ryogo Kubo as early as 1957 [31].

According to linear response theory, the frequency-dependent conductivity is proportional to the Fourier transform of the time-dependent auto-correlation function of the current density,

$$
<\mathbf{l}(0) \cdot \mathbf{l}(\mathrm{t})>=\mathrm{V}^{-2} \cdot \sum_{\mathrm{i}, \mathrm{j}}^{1 \ldots \mathrm{N}} \mathrm{q}_{\mathrm{i}} \mathrm{q}_{\mathrm{j}} \cdot<\mathbf{v}_{\mathrm{i}}(0) \cdot \mathbf{v}_{\mathrm{j}}(\mathrm{t})>
$$

In Eq. (1), $\mathbf{\imath}$ is the electric current density, $\mathrm{V}$ the volume of the sample and $\mathrm{N}$ the total number of ions, while charges and velocities are denoted by $q$ and $\mathbf{v}$, respectively. The summation is over both $\mathrm{i}$ and $\mathrm{j}$. The auto-correlation function of Eq. (1) may be viewed as consisting of two different components. One of them is due to the self-correlation of the velocity of any moving ion during any of its elementary displacements. As the duration of such a displacement may be estimated to be about 1 ps or less, this component has the form of a sharp positive peak at times not exceeding about 1 ps.

The ensuing relaxation processes cause a second component, which is a slowly decaying negative function of time approaching zero when the relaxation comes to an end. On the one hand, the DC conductivity, $\sigma_{\mathrm{DC}}$, as shown in Fig. 1, is given by the time integral over the entire auto-correlation function, $<\mathbf{l}(0) \cdot \mathbf{l}(\mathrm{t})>$. On the other, the integral over the short-time peak alone results in a much larger conductivity. The latter is the high-frequency (HF) conductivity, $\sigma_{\mathrm{HF}}$, which is attained in $\mathrm{CKN}$ at frequencies above $100 \mathrm{GHz}$, when the angular frequency exceeds the inverse of about $1 \mathrm{ps}$.

In Fig. 1, the temperature-dependent HF conductivity is shown along with the DC conductivity. How we arrive at $\sigma_{\mathrm{HF}}(\mathrm{T})$ on the basis of experimental data is outlined in Section 2 . As it turns out, a transition at $378 \mathrm{~K}$, already pointed out in Refs. 25 and 30, provides a major challenge in the derivation of $\sigma_{\mathrm{HF}}(\mathrm{T})$. Remarkably, this transition changes the shape of the conductivity spectrum, but at the same time leaves $\sigma_{D C}(T)$ continuous. It thus adds to the familiar structural and dynamic complexities that have been mentioned already. On the other hand, unexpected simplicities are found 
to emerge in the shape of $\sigma_{\mathrm{HF}}(\mathrm{T})$ and thus in the short-time dynamics. These include well-defined characteristics of the elementary ionic displacements, see Section 3. In a further step, comparison of the HF and DC data finally leads to an understanding of the $378 \mathrm{~K}$ transition. It marks the end of the transformation of molten CKN from a decoupled to a coupled ionic system, see Section 4, and is thus important with regard to both structure and dynamics.

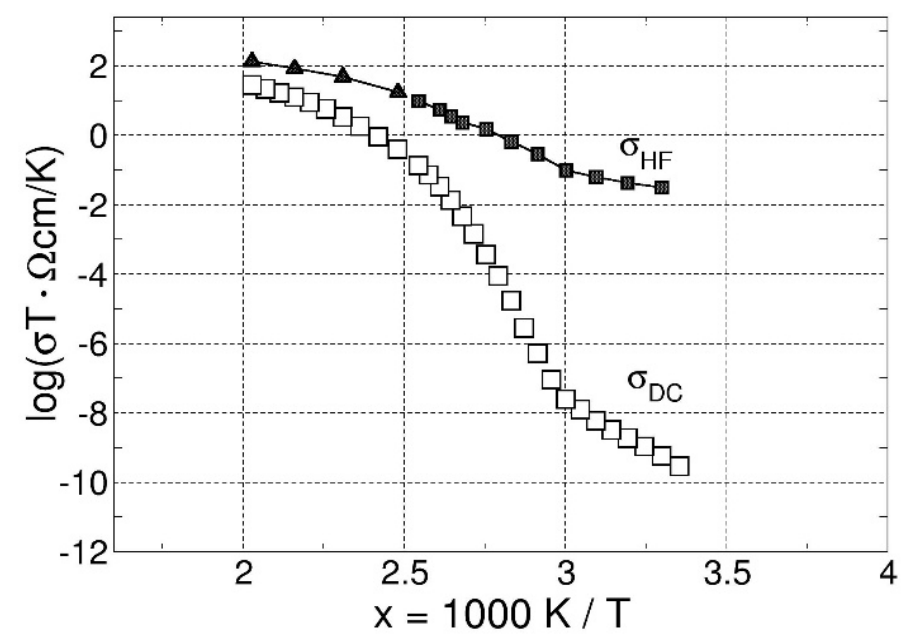

Fig. 1. Experimental DC conductivity of molten and glassy $C K N, \sigma_{D C}(x)$, along with the $H F$ conductivity, $\sigma_{\mathrm{HF}}(\mathrm{x})$, derived in Section 2. Note that the glass transition is near $\mathrm{x}=3.0$.

In Section 5, the results of Section 3 are combined with the pressure-dependent effects cited above. An even more comprehensive pattern of well-defined high-frequency behaviour is thus obtained, common to both melt and glass, across a wide range of temperatures. Here, the essential rôle is played by elastic forces. In answer to the question posed in the title of a paper by Scopigno et al. [32], we find that in the case of $\mathrm{CKN}$ the behaviour of the fragile liquid is indeed embedded within the properties of its glass.

\section{Presenting and Solving the CKN Puzzle}

The conductivity spectra of glass-forming CKN, to be discussed in this Section, are shown in Fig. 2. Here the original data [25], first published in 2005, are fitted by our present model conductivity isotherms, see also Figs. 5 and 6.

In Fig. 2, the most conspicuous feature is the sudden change in the onset frequency of the dispersion, observed at about $378 \mathrm{~K}$ or, when expressed in terms of $\mathrm{x}=1000 \mathrm{~K} / \mathrm{T}$, at $\mathrm{x} \approx 2.645$. This important feature was not detected by Howell, Bose, Macedo and Moynihan [7], since their highest experimental temperature was only $93.2^{\circ} \mathrm{C}$, corresponding to $\mathrm{x} \approx 2.73$.

Notably, the characteristics of the $\mathrm{CKN}$ conductivity isotherms differ from those of other fragile melts (such as $\mathrm{LiCl} \cdot 7 \mathrm{H}_{2} \mathrm{O}$ [28]) and of ionic liquids (such as $\mathrm{BMImBF}_{4}$ [28]) by not displaying Summerfield scaling [33]. In other words, the low-frequency sections of the conductivity isotherms do not superimpose when shifted in the plot of Fig. 2 along a straight line with a slope of 1 . This deviation from ordinary behaviour occurs in the form of three effects. (i) There is the step in the onset frequency at $378 \mathrm{~K}$. (ii) There is a change in the shape of the spectra, the onset of the dispersion being more gradual at low temperatures and more abrupt at high ones. (iii) Instead of one onset line with a slope of 1, there are two of them, with different slopes. These complications pose a puzzle, which will be addressed and solved in this Section. 


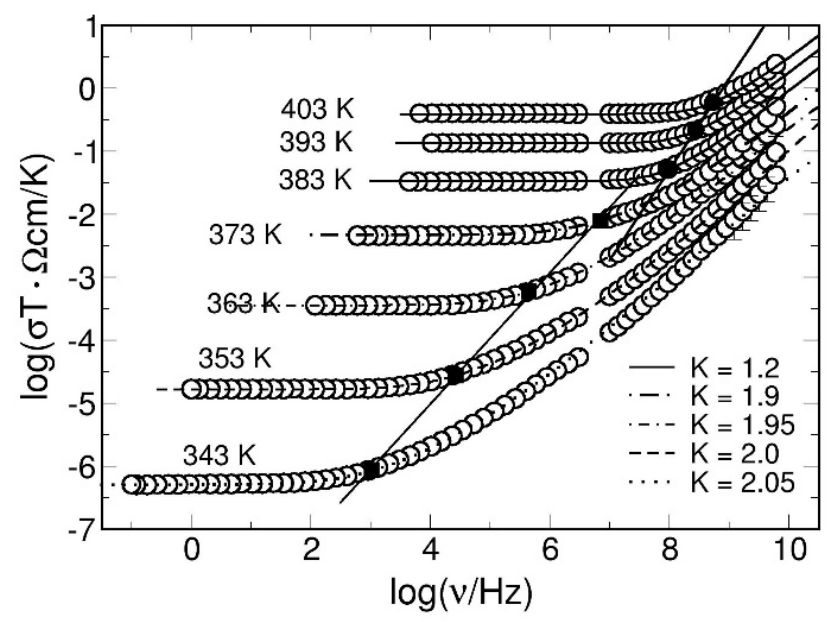

Fig. 2. Conductivity isotherms of $\mathrm{CKN}$ at various temperatures from $343 \mathrm{~K}$ up to $403 \mathrm{~K}$. The data have been fitted using the MIGRATION concept, see below. The black boxes and circles mark the onset frequencies of the dispersion, $v_{0}$, as defined in that model treatment, and the values of the shape parameter, $\mathrm{K}$, have been appropriately chosen. The discontinuity at $\mathrm{T} \approx 378 \mathrm{~K}$ gives evidence for a transition that went unnoticed in Fig. 1. Data taken from Ref. 25. For the model isotherms, see also Figs. 5 and 6.

In a first step towards modelling the conductivity spectra, we recall the connection between $\sigma(\omega)$ and $<\mathbf{l}(0) \cdot \mathbf{l}(\mathrm{t})>$. Here the sharp positive peak in $\langle\mathbf{l}(0) \cdot \mathbf{l}(\mathrm{t})>$ is expressed in terms of a delta function at $\mathrm{t}=0$, and the slowly decaying negative component in terms of the derivative of a decaying function of time, $\mathrm{W}(\mathrm{t})$, with $\mathrm{W}(0)=1$. We thus obtain

$$
\frac{\sigma(\omega)}{\sigma_{\mathrm{HF}}}=1+\int_{0^{+}}^{\infty} \frac{\mathrm{dW}(\mathrm{t})}{\mathrm{dt}} \cdot \cos (\omega \cdot \mathrm{t}) \cdot \mathrm{dt}
$$

In its low-frequency limit, Eq. (2) yields the relation $\sigma_{\mathrm{DC}} / \sigma_{\mathrm{HF}}=\mathrm{W}(\infty)$. In this Section, we will also use a parameter $\mathrm{B}$, defined as $\mathrm{B}=-\ln \mathrm{W}(\infty)$, and a scaled function, $\mathrm{W}_{\mathrm{S}}(\mathrm{t})=\mathrm{W}(\mathrm{t}) / \mathrm{W}(\infty)$.

To use Eq. (2) for deriving realistic model spectra, $\sigma(\omega)$, a robust dynamic criterion is required, which any suitable function, $\mathrm{W}(\mathrm{t})$, is expected to fulfil. Such a criterion is provided by the MIGRATION concept [26-28], in the form of the following rate equation:

$$
-\frac{\mathrm{d}}{\mathrm{dt}} \mathrm{W}_{\mathrm{S}}=\omega_{0} \cdot \mathrm{W}_{\mathrm{S}}^{2} \cdot\left(\ln \mathrm{W}_{\mathrm{S}}\right)^{\mathrm{K}}
$$

Note that Eq. (3) has been formed by combining the individual rate equations given, for instance, in Ref. 28. The meaning of the acronym, MIGRATION, is MIsmatch Generated Relaxation for the Accommodation and Transport of IONs. Experimental conductivity spectra are generally well described by the MIGRATION concept, see Ref. 28 and references cited therein.

Indeed, the dynamic principle expressed by Eq. (3) is now found to be valid in CKN as well, see below, with each of the CKN conductivity isotherms of Fig. 2 being perfectly reproduced by means of Eqs. (2) and (3). Four parameter values are required to construct a corresponding model spectrum. These may be chosen to be the DC conductivity, $\sigma_{\mathrm{DC}}$, the onset angular frequency, denoted by $\omega_{\mathrm{O}}$, the shape parameter, $\mathrm{K}$, and $\mathrm{B}=-\ln \mathrm{W}(\infty)$. The position of the spectrum in the log-log plot of $\sigma v s \omega$ is defined by $\sigma_{\mathrm{DC}}$ and $\omega_{\mathrm{O}}$, while its shape is determined by $\mathrm{K}$ and $\mathrm{B}$. More specifically, model spectra $\sigma(\omega)$, such as those in Fig. 2, are obtained from Eq. (2) by using functions W(t) that are derived by integrating Eq. (3). In the figure, the respective onset frequencies, $v_{O}=\omega_{\mathrm{O}} / 2 \pi$, have been marked by black boxes and circles, and it is seen what variations of the parameter $\mathrm{K}$ are needed to model the shape of the experimental spectra. 
Each of the conductivity isotherms in Fig. 2 can be reproduced by Eqs. (2) and (3), once $\sigma_{\mathrm{DC}}, \omega_{\mathrm{O}}$ and $\mathrm{K}$ are chosen as indicated in the figure, while the value of $\mathrm{B}$ may be arbitrarily large. However, leaving $\mathrm{B}(\mathrm{T})$ undefined leaves $\sigma_{H F}(\mathrm{~T})=\sigma_{\mathrm{DC}}(\mathrm{T}) \cdot \exp \mathrm{B}(\mathrm{T})$ undefined as well. At this point, a blueprint for a successful procedure towards deriving the HF conductivity, $\sigma_{H F}(T)$, is provided by those simpler examples, in which Summerfield scaling is valid, which means that $\sigma_{\mathrm{DC}} \mathrm{T} / \omega_{\mathrm{O}}$ and $\mathrm{K}$ are both temperature-independent. In those cases, VTF-type non-Arrhenius DC conductivities (roughly resembling those of molten $\mathrm{CKN}$ ) are perfectly reproduced by a modelling that starts out with an Arrhenius-activated HF conductivity and a temperature-independent end angular frequency of the dispersion, $\omega_{\mathrm{E}}[27,28,34]$. The latter assumption is equivalent to the view that an elementary displacement may be followed by a non-activated roll-back process [25, 29].

In this Section, the inverse procedure, i.e., the derivation of the temperature-dependent HF conductivity on the basis of the existing non-Summerfield data of Fig. 2, is shown to be possible, under the premise of $\omega_{\mathrm{E}}$ being constant. Unexpectedly, this possibility emerges from the fact that the required information is contained in the details of the $378 \mathrm{~K}$ transition, see below. However, before moving on to construct $\sigma_{\mathrm{HF}}(\mathrm{T})$, we present the temperature dependences of $\sigma_{\mathrm{DC}} \mathrm{T} / \omega_{\mathrm{O}}$ and $\mathrm{K}$, in Figs. 3 and 4 , respectively.

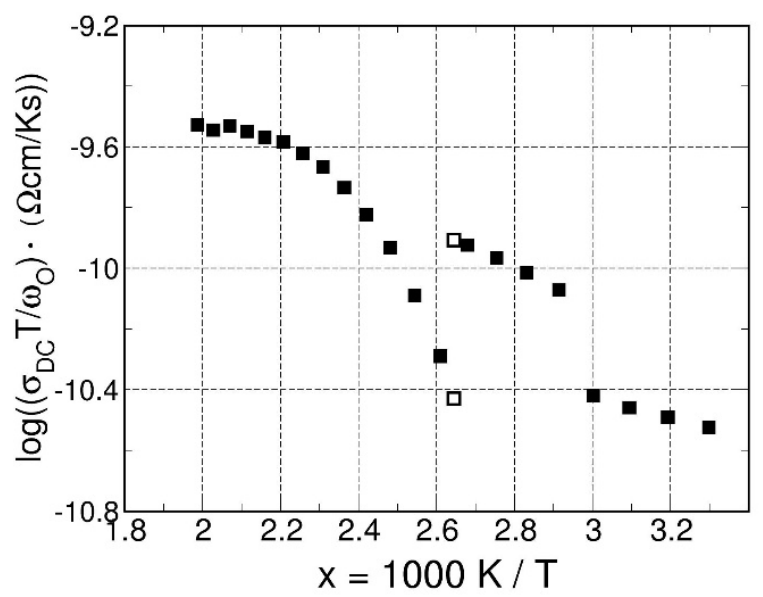

Fig. 3. Logarithmic plot of $\sigma_{D C} T / \omega_{O}$ versus inverse temperature. The open squares represent values of the ordinate obtained by extrapolation from either side towards the transition at $\mathrm{x}_{\mathrm{T}}=2.645$, giving a measure of the sudden change in the onset angular frequency, wo.

In Fig. 3, the most prominent feature is the sudden drop with decreasing $\mathrm{x}$, occurring at the $378 \mathrm{~K}$ transition, which is caused by the upward leap in $\omega_{\mathrm{O}}$. As the value of $\mathrm{x}$ is further decreased, $\sigma_{\mathrm{DC}} \mathrm{T} / \omega_{\mathrm{O}}$ shows a continuous increase. This corresponds to a slope of the onset line that is larger than one, see Fig. 2. Note also the obvious kink at $\mathrm{x} \approx 3.0$, i.e. at the glass transition.

The values of the shape parameter K, see Fig. 4, have been determined on the basis of a careful analysis using the MIGRATION concept for reproducing the experimental spectra. As expected, the $\mathrm{K}(\mathrm{x})$ data points show a sharp increase, from 1.2 to 1.9 , at the $378 \mathrm{~K}$ transition, i.e. at the same position on the inverse temperature scale where the discontinuity is found in $\sigma_{\mathrm{DC}} \mathrm{T} / \omega_{\mathrm{O}}$. Note that, while this transition is not seen in the DC conductivity, the glass transition at $\mathrm{x} \approx 3.0$ is, by contrast, not visible in $\mathrm{K}(\mathrm{x})$.

The two simultaneous discontinuities occurring in molten $\mathrm{CKN}$ at its $378 \mathrm{~K}$ transition, i.e. those of $\omega_{\mathrm{O}}$ and $\mathrm{K}$, do not only pose an intriguing puzzle, but also contain the key to its solution. As it turns out, the key is in regarding the two discontinuities as closely related and, at the same time, regarding the end angular frequency of the dispersion, $\omega_{\mathrm{E}}$, as temperature-independent (as in other fragile melts showing VTF behaviour). 


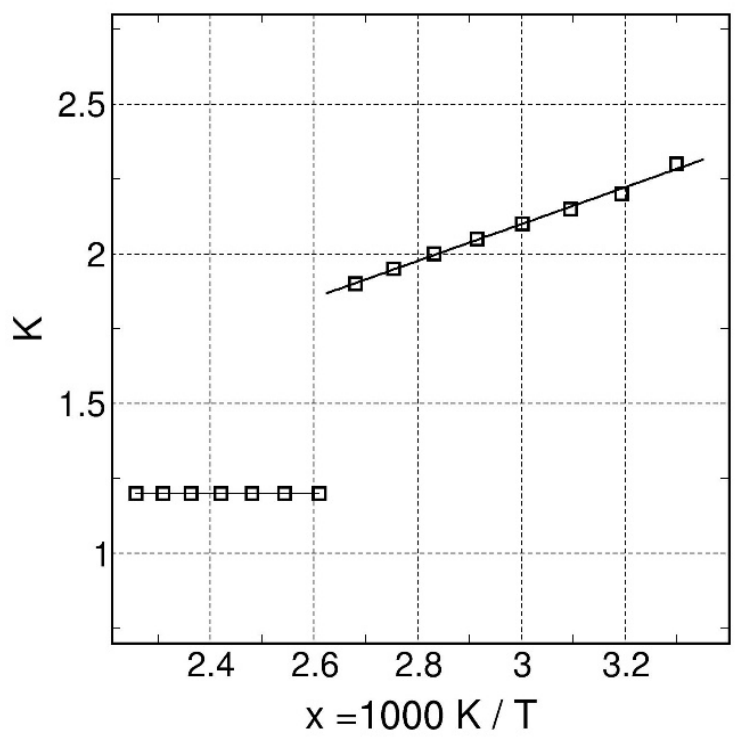

Fig. 4. The shape parameter $\mathrm{K}$ as a function of inverse temperature. For each isotherm, the value of $\mathrm{K}$ can be determined to an accuracy of 0.05 .

To introduce $\omega_{\mathrm{E}}$ in the framework of the MIGRATION concept, we consider Eq. (3) in its shorttime limit. In this limit, with $\mathrm{W}(\mathrm{t})$ and $\ln \mathrm{W}(\mathrm{t})$ approaching 1 and 0 , respectively, the expression $\ln \mathrm{W}_{\mathrm{S}}$, which is equal to $\ln (\mathrm{W} / \mathrm{W}(\infty))=\ln \mathrm{W}+\mathrm{B}$, may be approximated by $\mathrm{B}$, if $\mathrm{B}>>|\ln \mathrm{W}|$ holds true. When formulated in terms of $\mathrm{W}(\mathrm{t})$ instead of $\mathrm{W}_{\mathrm{S}}(\mathrm{t})$, Eq. (3) thus becomes

$$
-\frac{d W}{d t} \cong \omega_{O} \cdot e^{B} \cdot W^{2} \cdot B^{K} \quad \text { in the short-time limit. }
$$

Equation (4) is solved by

$$
\mathrm{W}(\mathrm{t})=\frac{1}{1+\omega_{\mathrm{E}} \mathrm{t}}
$$

with

$$
\begin{aligned}
& \omega_{E}=\omega_{O} \cdot e^{B} \cdot B^{K} \\
& \ln \left(\frac{\omega_{E}}{\omega_{O}}\right)=K \cdot \ln B+B .
\end{aligned}
$$

This implies $\mathrm{W}\left(1 / \omega_{\mathrm{E}}\right)=1 / 2$ and, approximately, $\sigma\left(\omega_{\mathrm{E}}\right) / \sigma_{\mathrm{HF}}=1 / 2[29,35]$. In view of the above requirement, $B>>\mid \operatorname{lnWl}$, the definition given for $\omega_{\mathrm{E}}$ in Eq. (6) is valid as long as $\mathrm{B}$ is much larger than $\ln 2$. As a matter of experience, Eqs. (6) and (7) may be safely applied as long as B does not become smaller than 4 .

The (temperature-independent) numerical value of $\omega_{\mathrm{E}}$ is now derived by considering Eq. (6) on either side of the $378 \mathrm{~K}$ transition, assuming that B is continuous. Denoting the temperature regimes above and below the transition by indices 1 and 2, respectively, and the transition itself by an index $\mathrm{T}$, we may write $\omega_{\mathrm{E} 1}=\omega_{\mathrm{E}}=\omega_{\mathrm{E} 2}$ at $\mathrm{x}=\mathrm{x}_{\mathrm{T}}$ and thus obtain the following identity:

$$
\ln \left(\frac{\omega_{\mathrm{O} 1}}{\omega_{\mathrm{O} 2}}\right)_{\mathrm{T}}=\left(\mathrm{K}_{2}-\mathrm{K}_{1}\right) \cdot \ln \mathrm{B}_{\mathrm{T}} .
$$


Inserting $\left(\omega_{\mathrm{O} 1} / \omega_{\mathrm{O} 2}\right)_{\mathrm{T}}=3.3$ (from Fig. 3) and $\mathrm{K}_{2}-\mathrm{K}_{1}=1.9-1.2=0.7$ (from Fig. 4) yields $\mathrm{B}_{\mathrm{T}} \approx$ 5.5 and, hence, a value for $\sigma_{\mathrm{HF}} \mathrm{T}\left(\mathrm{x}_{\mathrm{T}}\right)$ which is above $\sigma_{\mathrm{DC}} \mathrm{T}\left(\mathrm{x}_{\mathrm{T}}\right)$ by $5.5 / \ln 10 \approx 2.4$ decades, cf. Fig. 1 . In passing we note that $\mathrm{B}_{\mathrm{T}}$ is indeed large enough to justify the use of Eqs. (6), (7), (8). Once $\mathrm{B}_{\mathrm{T}}$ is known, Eq. (6) can be used to derive the end angular frequency, $\omega_{\mathrm{E}}$. By construction, cf. Eq. (8), identical results are obtained with $\mathrm{B}_{\mathrm{T}}, \omega_{\mathrm{O} 1 \mathrm{~T}}, \mathrm{~K}_{1}$ and with $\mathrm{B}_{\mathrm{T}}, \omega_{\mathrm{O} 2 \mathrm{~T}}, \mathrm{~K}_{2}$. We find $\log \left(\omega_{\mathrm{E}} \cdot \mathrm{s}\right) \approx 11.9$. In other words, $\omega_{\mathrm{E}}$ is about the inverse of $1 \mathrm{ps}$, confirming the estimate made in Section 1.

The temperature-dependent HF conductivity of CKN, as shown in Fig. 1, is now derived by the following procedure. Note that this is where we use our key assumption that $\omega_{\mathrm{E}}$ is temperatureindependent in CKN (as in other fragile melts, see above).

(i) At each temperature, $\ln \left(\omega_{\mathrm{E}} / \omega_{\mathrm{O}}\right)$ is formed from $\omega_{\mathrm{E}}$ (with a constant value of $10^{11.9} \mathrm{~s}^{-1}$ ) and $\omega_{0}$ (as read from the conductivity spectra).

(ii) The value of $\mathrm{B}$ is then determined. For $\mathrm{B}>4$ this is done via Eq. (7), whereas a different technique must be applied for $\mathrm{B} \leq 4$, see below.

(iii) According to the definition of $\mathrm{B}, \sigma_{\mathrm{HF}}$ is finally obtained as $\sigma_{\mathrm{HF}}=\sigma_{\mathrm{DC}} \cdot \exp \mathrm{B}$.

For determining B, Eqs. (6) and (7) could be safely applied in the entire x-range above 2.5. In Fig. 1 , the respective HF conductivities have been marked by black boxes. For $\mathrm{x} \leq 2.5$, however, $\mathrm{B}>4$ no longer holds, and a different and even more direct procedure was employed to find the proper values of B. ${ }^{\ddagger}$ In Fig. 1, the HF conductivities thus obtained have been marked by black triangles. As a result, $\sigma_{\mathrm{HF}}(\mathrm{x})$ is found to be continuous not only at $\mathrm{x}=\mathrm{x}_{\mathrm{T}}$, but also at $\mathrm{x}=2.5$, where different procedures for determining $\mathrm{B}$ have been employed on either side. A thorough discussion of the temperaturedependent HF conductivity will be given in the following Section.

Model conductivity spectra, $\sigma(\omega)$, may now be constructed for molten CKN at different temperatures, the required parameters, $\sigma_{\mathrm{DC}}, \omega_{\mathrm{O}}, \mathrm{B}$ and $\mathrm{K}$, being all known. A set of such spectra is presented in Fig. 5.

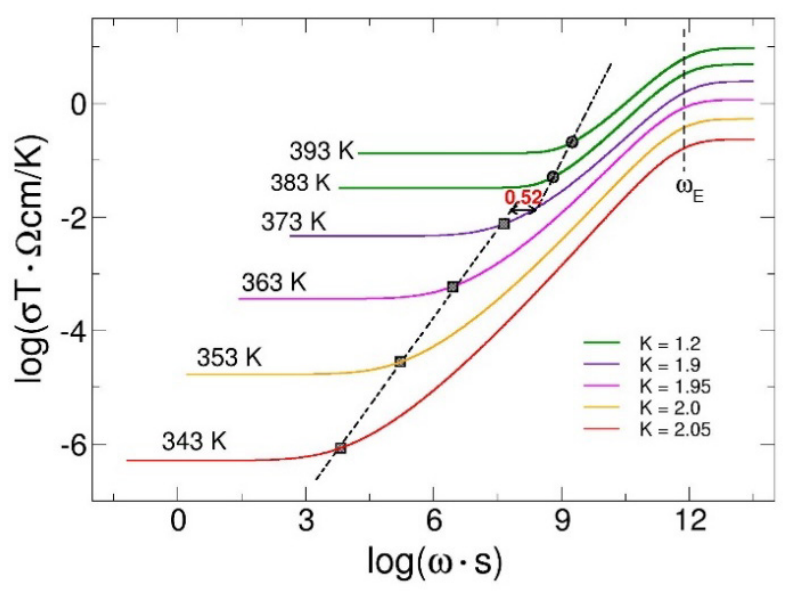

Fig. 5. Set of model conductivity isotherms for molten CKN, constructed from the MIGRATION concept formalism and reproducing the experimental data of Figs. 2, 3 and 4.

\footnotetext{
$\$$ First of all, the model curves at $383 \mathrm{~K}, 393 \mathrm{~K}$ and $403 \mathrm{~K}$ were superposed with a vibrational component and found to reproduce the experimental spectra. The factor $\mathrm{A}$ in the vibrational component $\sigma_{\text {vib }}=\mathrm{A} \omega^{2}$ was found to be constant. The same vibrational component was used for higher temperatures to choose values of $\mathrm{B}$ and $\sigma_{\mathrm{HF}}$, which were then employed to construct model isotherms. The experimental spectra were indeed found to be fully described by superposition of the two components.
} 
The conductivity isotherms of Fig. 5 nicely reproduce the experimental data, as has been demonstrated in Fig. 2 already. Note the step in $\log \omega_{\mathrm{O}}$ at $378 \mathrm{~K}$ and the constancy of $\omega_{\mathrm{E}}$. The temperature dependences of the DC and HF conductivities are those shown in Fig. 1. It is also worth mentioning that both experimental and model isotherms do not follow a power law in the dispersive regime and that relaxation effects are still significant at $\mathrm{GHz}$ frequencies.

In Fig. 6, experimental data for the frequency-dependent conductivity of molten CKN, taken at $363 \mathrm{~K}$ and comprising frequencies up to about $100 \mathrm{GHz}$, are compared with the corresponding model spectrum.

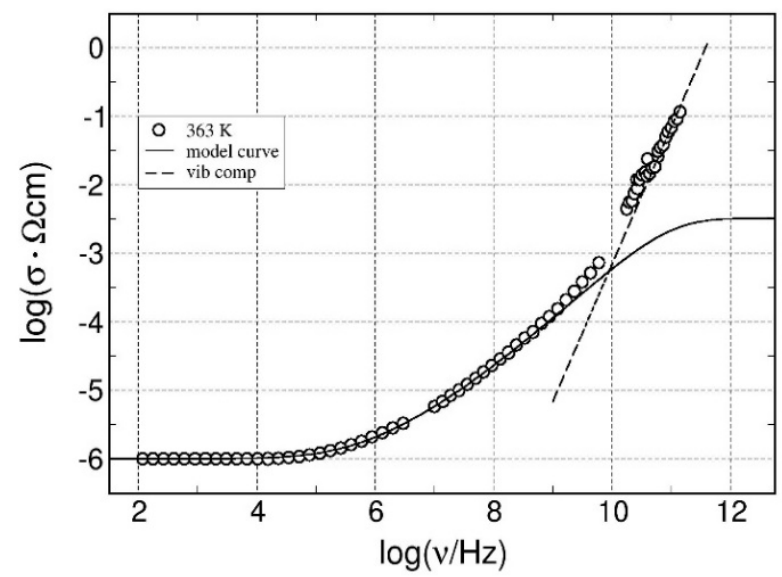

Fig. 6. Experimental conductivity data of molten $\mathrm{CKN}$, taken at $363 \mathrm{~K}$, being well reproduced by superimposing two components, one of them translational, here modelled by the MIGRATION concept, and the other vibrational, its low-frequency flank increasing as frequency squared.

Obviously, the experimental conductivity data are well reproduced by a superposition of two components. One of them is the model spectrum already shown in Fig. 5. The other is the lowfrequency flank of the lowest-lying vibrational mode, characterised by a $\sigma_{\mathrm{vib}} \propto \omega^{2}$ frequency dependence. ${ }^{\ddagger}$ The corresponding straight line with a slope of two has been included in the figure. Here we want to emphasise that contrary to differing suggestions made in the literature $[16,23,36]$, the experimental data are reproduced without introducing any additional 'caged motion' or 'nearly constant loss' effects. As pointed out earlier [28, 37], it is sufficient to superimpose the translational and vibrational components.

\section{Elementary Displacements}

Notably, the dynamic complexities of an ionic fluid, which are related to its rapid structural changes, are no longer seen when the system is viewed in a sufficiently narrow time window. Indeed, the structure appears to be 'arrested' in a solid-like fashion, if the width of the time window is chosen to be less than about one picosecond, corresponding to HF-plateau frequencies. In this frequency regime, the only translational movements seen are elementary displacements of individual ions, while any subsequent roll-back motion of the ion itself as well as induced movements of other ions are outside the considered time window. Clear-cut results are therefore expected to emerge from an analysis of the HF conductivity data, which were first presented in Fig. 1 and are now shown again in Fig. 7.

To start our discussion, we first consider CKN glass, in which potassium ions are known to be mobile. The HF conductivity resulting from their elementary displacements (hops) may be formulated in the spirit of the DC analogue connecting diffusion and conduction:

$$
\sigma_{\mathrm{HF}} \mathrm{T}=\Gamma_{0} \cdot \mathrm{a}^{2} \cdot \mathrm{n} \cdot \mathrm{c}
$$




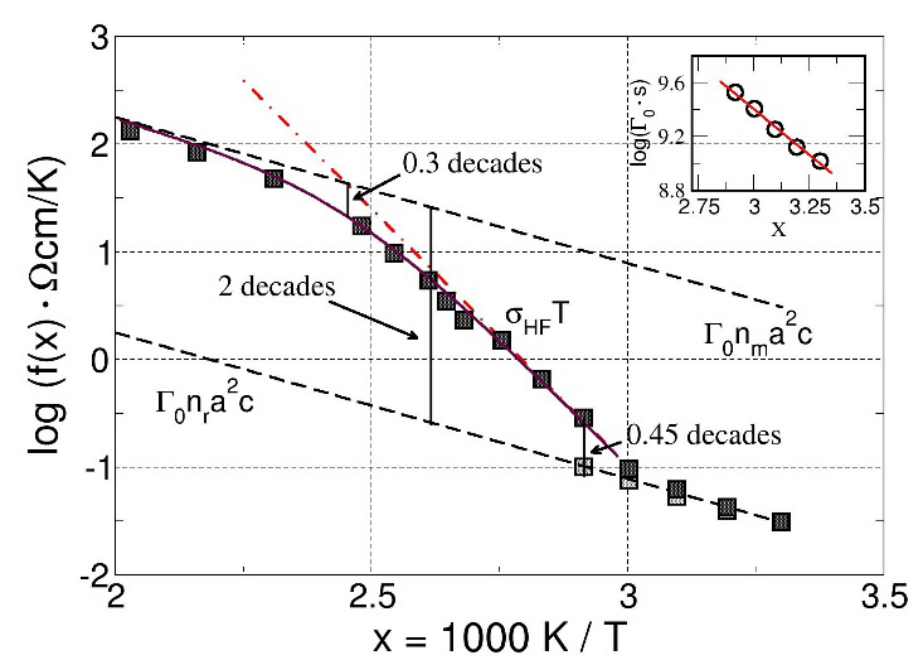

Fig. 7. Logarithmic plot of four functions, $f(x)$, versus $x$. These are $\sigma_{H F} T=\Gamma_{0} a^{2} n c$ (filled squares), $\Gamma_{0} \mathrm{a}^{2} \mathrm{n}_{\mathrm{r}} \mathrm{c}$ (open squares and lower straight line), $\Gamma_{0} \mathrm{a}^{2} \mathrm{n}_{\mathrm{A}} \mathrm{c}$ (dash-dotted line) and $\Gamma_{0} \mathrm{a}^{2} \mathrm{n}_{\mathrm{m}} \mathrm{c}$ (upper straight line). See text for details.

Here, $\mathrm{n}$ is the number density of mobile potassium ions in the glass and thus the same as the number density of available 'target sites' that enable $\mathrm{K}^{+}$ions to contribute to the HF conductivity. The notations $\mathrm{a}^{2}$ and $\Gamma_{0}$ stand for the squared distance and the rate of elementary hops, respectively. For simplicity, an abbreviation has been introduced: $\mathrm{c}=\mathrm{e}^{2} /\left(6 \mathrm{k}_{\mathrm{B}}\right)$, where $\mathrm{k}_{\mathrm{B}}$ is the Boltzmann constant, and e denotes the electronic charge.

In the glass, $\mathrm{a}^{2}$ is supposed to be the same for an 'elementary' hop and for a 'successful' one, being given by the glassy structure and remaining unchanged during the relaxation process. We thus obtain the identity $\sigma_{\mathrm{DC}} / \sigma_{\mathrm{HF}}=\omega_{\mathrm{O}} / \Gamma_{0}$ and may use it to reformulate $\sigma_{\mathrm{DC}} \mathrm{T} / \omega_{\mathrm{O}}$, see Fig. 3 , as $\sigma_{\mathrm{HF}} \mathrm{T} / \Gamma_{0}$. Therefore, the elementary hopping rate of the mobile charge carriers in the glass, $\Gamma_{0}$, can be conveniently expressed in terms of $\sigma_{\mathrm{HF}} \mathrm{T}$ from Figs. 1 and 7 and $\sigma_{\mathrm{DC}} \mathrm{T} / \omega_{\mathrm{O}}$ from Fig. 3:

$$
\Gamma_{0}=\frac{\sigma_{\mathrm{HF}} \mathrm{T}}{\sigma_{\mathrm{DC}} \mathrm{T} / \omega_{\mathrm{O}}}
$$

The value of $\Gamma_{0}$ turns out to be of the order of $10^{9} \mathrm{~s}^{-1}$ in CKN glass, its temperature dependence being well described by an Arrhenius law. The activation energy is only about $26 \mathrm{~kJ} / \mathrm{mol}$, see the inset of Fig. 7.

Here we introduce $\mathrm{x}_{\mathrm{r}}=3.3$ as a reference value on the inverse temperature scale, and denote $\mathrm{n}\left(\mathrm{x}_{\mathrm{r}}\right)$ by $\mathrm{n}_{\mathrm{r}}$. At $\mathrm{x}_{\mathrm{r}}$, we find $\sigma_{\mathrm{HF}} \mathrm{T} / \Gamma_{0}=\sigma_{\mathrm{DC}} \mathrm{T} / \omega_{\mathrm{O}} \approx 10^{-10.5} \mathrm{Ks} /(\Omega \mathrm{cm})$, see Fig. 3. Equation (9) is now used to determine $\mathrm{n}_{\mathrm{r}} \cdot \mathrm{a}^{2}$, which (with $\mathrm{c} \approx 10^{-15.5} \mathrm{Ks} / \Omega$ ) turns out to be about $0.01 \mathrm{~nm}^{-1}$. Later on, the values of $\mathrm{n}_{\mathrm{r}}$ and $\mathrm{a}^{2}$ will be derived separately.

Considering $\sigma_{\mathrm{HF}} \mathrm{T}$ in the glass, at $3.0 \leq \mathrm{x} \leq 3.3$, the temperature dependence of this quantity can be regarded as resulting from the temperature dependences of each factor in $\left(n / n_{r}\right) \cdot\left(\Gamma_{0} a^{2} n_{r} c\right)$. The former is the normalised number density, and the latter contains the temperature dependence only of the elementary hopping rate, since $\mathrm{n}_{\mathrm{r}} \cdot \mathrm{a}^{2}$ is a constant. Note that, at the glass transition, $\mathrm{x} \approx 3.0$, the number density of available 'target sites' is thus found to be about $4 / 3$ its value at $x=3.3$. In Fig. 7 , this can be read from the values of the filled and open squares at $\mathrm{x}=3.0$.

We now proceed to the molten-salt regime just above $\mathrm{T}_{\mathrm{g}}$, where both DC and HF conductivity are again Arrhenius, but with higher activation energies than in the glass. At the glass transition itself, similar kinks are present in $\sigma_{\mathrm{HF}} \mathrm{T}$, see Figs. (1) and (7), and in $\sigma_{\mathrm{DC}} \mathrm{T} / \omega_{\mathrm{O}}$, see Fig. 3. Forming the ratio of these quantities according to Eq. (10) not only in the glass, but also for the data point at $\mathrm{x}=2.91$, we find that $\Gamma_{0}$ follows the same Arrhenius law on either side of the glass transition, cf. Fig. 7. Therefore, the origin of the kinks at $\mathrm{x}=3.0$ is not to be seen in a change of the barrier height for elementary hops, but in a change of the rate at which new target sites are created with decreasing $\mathrm{x}$. 
At $x=2.91$, for instance, their number density is already more than twice its value at $x=3.0$. This can be seen from the amount at which the distance between the filled and open squares increases with decreasing $\mathrm{x}$.

The assumption made above in deriving Eq. (10), i.e. that a solid-like network persists during the relaxation process, may still hold at $\mathrm{x}=2.91$. It is clear though that this assumption is bound to become increasingly invalid at higher temperatures. Therefore, another procedure is required in order to evaluate the $\mathrm{HF}$ conductivity data of molten $\mathrm{CKN}$, comprising the entire temperature range from $\mathrm{T}_{\mathrm{g}}$ up to $500 \mathrm{~K}$, i.e. for $2.0<\mathrm{x}<3.0$, see Fig. 7.

For this purpose, Eq. (9) can be used again, but $n=n(x)=n_{K}(x)$ must be replaced by a function that allows for all three kinds of mobile ions, $n=n(x)=n_{K}(x)+n_{N O 3}(x)+4 n_{C a}(x)$. Here the factor of four is due to the fact that contributions to the HF conductivity are always proportional to charge squared, cf. Eq. (1). Of course, conductivity measurements do not distinguish between different ionic species. Therefore, our data contain no information on their individual number densities. Also, the product, $\Gamma_{0}(\mathrm{x}) \mathrm{a}^{2}$, must be regarded as an average.

In the current Section, an unexpected simplicity will soon be seen to emerge. For a sketch of its essence, let us consider the solid line in Fig. 7, which reproduces the experimental data for $\sigma_{H F} \mathrm{~T}$ in molten CKN. This line is obtained in a remarkably simple fashion: Each of the two components that make up $\sigma_{\mathrm{HF}} \mathrm{T}$, namely $\Gamma_{0} \mathrm{a}^{2}$ and n, see Eq. (9), has a temperature dependence that results from just one specific activation energy. Surprisingly, these two energies seem to be constant over the entire temperature range. They are $\mathrm{E}_{\mathrm{ed}}$, required for an elementary displacement, and $\mathrm{E}_{\mathrm{f}}$, required for making an immobile ion mobile by suitably changing its immediate neighbourhood, thus opening up a new target site.

Towards this finding, the following observation is essential. Inspection of Fig. 7 suggests that near $500 \mathrm{~K}$, in the logarithmic representation of that figure, $\sigma_{\mathrm{HF}} \mathrm{T}$ approaches a straight line, which appears to be parallel to the one derived earlier for $\Gamma_{0}(x) a^{2} n_{r} c$, on either side of the glass transition (line connecting the open squares in Fig. 7). At high temperatures, the HF conductivity thus seems to be directly proportional to a rate of elementary ionic displacements which, regarding the required activation energy, cannot be distinguished from that in the glass. The two straight lines being parallel suggests that, in the high temperature limit, the number density of the mobile charge carriers attains a constant final value. For simplicity, all the ions in the melt may now be regarded as mobile and contributing to $\sigma_{\mathrm{HF}} \mathrm{T}$. In Fig. 7 , the corresponding maximum value of $\mathrm{n}(\mathrm{x})$ is denoted by $\mathrm{n}_{\mathrm{m}}$, and the upper straight line thus represents $\Gamma_{0}(x) a^{2} n_{m} c$.

The (far-reaching) assumption that $\Gamma_{0}(\mathrm{x}) \mathrm{a}^{2}$ remains the same function from $300 \mathrm{~K}$ in the glass up to $500 \mathrm{~K}$ in the melt appears acceptable only if the ratio, $\sigma_{\mathrm{HF}} \mathrm{T} /\left(\Gamma_{0}(\mathrm{x}) \mathrm{a}^{2} \mathrm{c}\right)$, qualifies as a number density function $\mathrm{n}(\mathrm{x})$ with a suitable temperature dependence. Here $\mathrm{n}(\mathrm{x}) / \mathrm{n}_{\mathrm{m}}$ is understood as the fraction of those 'mobile' ions (more exactly: ionic charges) which, at any given instant of time, are in a geometrical position that enables them to perform an elementary displacement. Note also that mobile and immobile ions may rapidly change identity in the fluid melt, while $n(x) / n_{m}$ stays fixed at any given temperature.

Considering $\sigma_{\mathrm{HF}} \mathrm{T} /\left(\Gamma_{0}(\mathrm{x}) \mathrm{a}^{2} \mathrm{c}\right)$ in $\mathrm{CKN}$ at temperatures above the glass transition, cf. Fig. 7 , we first observe an Arrhenius-type increase, which may have been expected for a function $\mathrm{n}(\mathrm{x})$. In this activated process, newly available target sites are supposed to be created, enabling neighbouring ions to perform elementary displacements. Close to $T_{g}$ these are mainly potassium ions, while more and more nitrate ions are expected to become mobile as well at smaller values of $\mathrm{x}$ [8].

The dash-dotted straight line in Fig. 7 results from an Arrhenius ansatz not only for $\Gamma_{0}(\mathrm{x})$, but also for the number density function, with $\mathrm{E}_{\mathrm{f}}$ denoting the formation energy for mobile ionic charges:

$$
\begin{gathered}
\Gamma_{0}(\mathrm{x})=29.6 \mathrm{ps}^{-1} \cdot \exp (-3.12 \mathrm{x}) \\
\text { with } \mathrm{E}_{\mathrm{ed}}=3.12 \cdot \mathrm{R} \cdot 1000 \mathrm{~K} \approx 26 \mathrm{~kJ} / \mathrm{mol} \\
\mathrm{n}_{\mathrm{A}}(\mathrm{x})=\mathrm{n}(3.0) \cdot \exp (7.85 \cdot(3.0-\mathrm{x})) \\
\text { with } \mathrm{E}_{\mathrm{f}}=7.85 \cdot \mathrm{R} \cdot 1000 \mathrm{~K} \approx 65.4 \mathrm{~kJ} / \mathrm{mol}
\end{gathered}
$$


The reason why the dash-dotted straight line in Fig. 7 does not reproduce the experimental data any more as $\mathrm{x}$ becomes less than about 2.7 is quite evident. For $\mathrm{n}(\mathrm{x})=\mathrm{n}_{\mathrm{A}}(\mathrm{x})$ to be valid, the reservoir of immobile ions that can be transformed into mobile ones would have to be unlimited. However, the fraction of available immobile ions (or, rather, ionic charges) is not 1 , but only $1-n / n_{m}$. This implies that $\mathrm{n}(\mathrm{x})=\mathrm{n}_{\mathrm{A}}(\mathrm{x})$ must be replaced by $\mathrm{n}(\mathrm{x})=\mathrm{n}_{\mathrm{A}}(\mathrm{x}) \cdot\left(1-\mathrm{n}(\mathrm{x}) / \mathrm{n}_{\mathrm{m}}\right)$, which is equivalent to

$$
\frac{1}{\mathrm{n}(\mathrm{x})}=\frac{1}{\mathrm{n}_{\mathrm{m}}}+\frac{1}{\mathrm{n}_{\mathrm{A}}(\mathrm{x})} \text {. }
$$

When $\mathrm{n}(\mathrm{x})$ is taken from Eqs. (13) and (12) and $\Gamma_{0}(\mathrm{x})$ from Eq. (11), then Eq. (9) is found to yield the solid line in Fig. 7, which reproduces the measured HF conductivities of CKN in the entire moltensalt temperature range. This means that the structure and dynamics of molten $\mathrm{CKN}$, when viewed in a sub-picosecond time window, are both characterised by surprising simplicities: Not only does the activation energy for an elementary displacement, $\mathrm{E}_{\text {ed }}$, appear to remain constant from $300 \mathrm{~K}$ in the glass up to $500 \mathrm{~K}$ in the fluid melt; moreover, at temperatures above the glass transition, the CKN melt is found to display a constancy of the formation energy for mobile ionic charges, $\mathrm{E}_{\mathrm{f}}$.

Finally, the vertical distance between the two straight lines in Fig. 7, which amounts to about two decades, can be used to estimate the absolute value of $\mathrm{n}_{\mathrm{r}}$ and, subsequently, the width of an elementary displacement, a. If $\mathrm{n}_{\mathrm{m}}$ corresponds to all ionic charges in a sample of CKN, then $\mathrm{n}_{\mathrm{r}} \approx \mathrm{n}_{\mathrm{m}} / 100$ corresponds to about $6.0 \%$ of the potassium ions and thus to the same number of target sites at $\mathrm{x}_{\mathrm{r}}=$ 3.3. From a density of CKN glass of $2.3 \mathrm{~g} / \mathrm{cm}^{3}$, see Ref. 8 , we find that $6.0 \%$ is equivalent to $\mathrm{n}_{\mathrm{r}} \approx$ $0.40 \mathrm{~nm}^{-3}$. Further, taken together with $\mathrm{n}_{\mathrm{r}} \cdot \mathrm{a}^{2} \approx 0.01 \mathrm{~nm}^{-1}$ as derived earlier, we obtain $\mathrm{a} \approx 0.16 \mathrm{~nm}$, which appears reasonable. The apparent constancy of this distance from $300 \mathrm{~K}$ up to $500 \mathrm{~K}$ may be interpreted as a preservation of essential characteristics of the short-time structure, despite the evident fragility of the melt.

\section{The 378 K Transition}

We note that in the previous Section no indication of the $378 \mathrm{~K}$ transition could be seen in the subpicosecond behaviour of molten CKN. Here we show that when the salient simple features detected at short times are combined with the long-time properties, new insights are obtained into the temperature-dependent structure and dynamics of molten CKN.

In this context, the most obvious finding concerns the rôle of the number density function, $\mathrm{n}(\mathrm{x})$, as described by Eqs. (12) and (13). In the entire temperature regime above $378 \mathrm{~K}$, i.e. at $2.0<\mathrm{x}<2.645$, the $\mathrm{x}$-dependent function $\sigma_{\mathrm{DC}} \mathrm{T} / \omega_{\mathrm{O}}$, see Fig. 3, is found to be exactly proportional to $\mathrm{n}(\mathrm{x})$. Therefore, the deviation from Summerfield scaling, observed at $2.0<\mathrm{x}<2.645$, is entirely due to the dependence of the number density function on inverse temperature, $n(x)$. Here we recall that $n(x) / n_{m}$ denotes the fraction of ionic charges which, at any given instant of time, are able to perform elementary

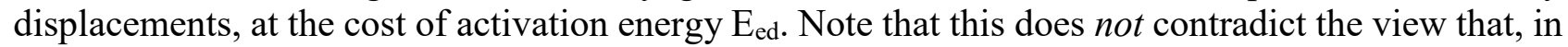
a highly fluid melt, all ions are moving in a longer time window, for instance during a charge relaxation process.

Considering the DC analogue of Eq. (9),

$$
\sigma_{\mathrm{DC}} \mathrm{T}=\omega_{0} \cdot l^{2} \cdot \mathrm{n} \cdot \mathrm{c}
$$

we now realise that the constancy of $\sigma_{\mathrm{DC}} \mathrm{T} /\left(\omega_{\mathrm{O}} \cdot \mathrm{n}\right)$, observed at temperatures above $378 \mathrm{~K}$, implies a constancy of $l$. Here $l$ is the characteristic length of those charge displacements, occurring at rate $\omega_{\mathrm{O}}$, which constitute the random steps of macroscopic diffusive motion and may be regarded as outcomes of elementary displacements plus charge relaxation. 
The proportionality of $\sigma_{\mathrm{DC}} \mathrm{T} / \omega_{\mathrm{O}}$ and $\mathrm{n}$ ends abruptly at the $378 \mathrm{~K}$ transition, cf. Figs. 3 and 7 , due to the sudden change in $\omega_{0}$. According to Eq. (14), this implies a sudden change in $l$ as well, since both $\sigma_{\mathrm{DC}} \mathrm{T}$ and $\mathrm{n}$ are continuous. To derive the variation of $l$ with inverse temperature in the entire range of our present study, we combine Eqs. (9) and (14) and thus obtain

$$
\left(\frac{l}{\mathrm{a}}\right)^{2}=\frac{\sigma_{\mathrm{DC}} \mathrm{T} / \omega_{\mathrm{O}}}{\sigma_{\mathrm{HF}} \mathrm{T} / \Gamma_{\mathrm{O}}}
$$

with $\sigma_{\mathrm{DC}} \mathrm{T} / \omega_{\mathrm{O}}$ and $\sigma_{\mathrm{HF}} \mathrm{T} / \Gamma_{0}$ to be read from Figs. 3 and 7 , respectively. Here, a $\approx 0.16 \mathrm{~nm}$ is again the constant length of an elementary displacement.

The resulting function, $l(\mathrm{x}) / \mathrm{a}$, is shown in Fig. 8. Starting out from 1.0 in the glass and near $\mathrm{T}_{\mathrm{g}}$, a rapid decay of $l(\mathrm{x}) / \mathrm{a}$ is observed with decreasing $\mathrm{x}$, ending in a final drop at $\mathrm{x} \approx 2.645$, i.e. at the 378 $\mathrm{K}$ transition. The constant value found at $\mathrm{x}<2.645$ is about 0.3 .

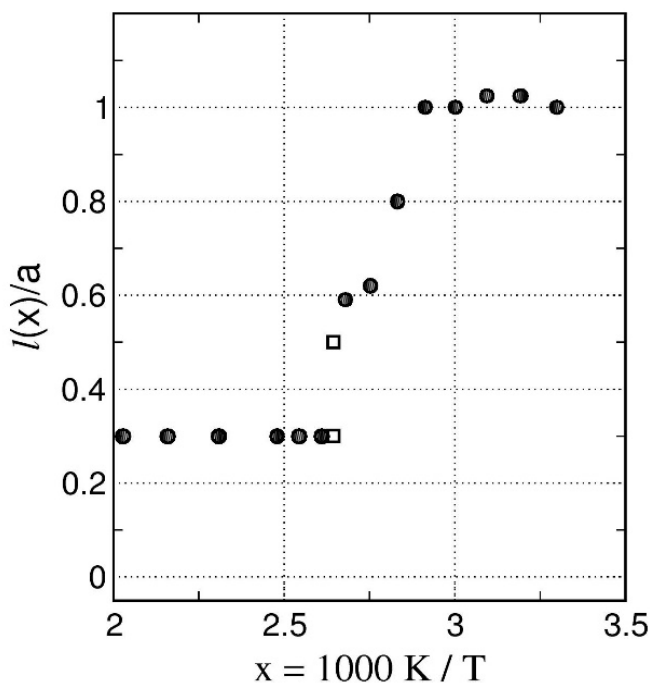

Fig. 8. The ratio of the characteristic length of charge displacement, $l(x)$, see the main text, to that of an elementary displacement, a, as obtained from Eq. (15). The open squares correspond to the open squares in Fig. 3.

This fall-off from 1.0 to 0.3 reflects the decay of network structures with increasing temperature, experienced by the mobile ions and thus observed on the time scale of their charge relaxation processes. This may be visualised as follows.

In the glass, charge relaxation (in the form of a redistribution of rather distant charge carriers) is slow, but it is still much faster than any structural changes. Therefore, a potassium ion still finds itself at its target site when the relaxation is (successfully) finished, implying $l=a$. On the other hand, $l<$ a means that the ion cannot wait at a fixed target site until the redistribution of its (now nearby) neighbours is completed. At that time, its distance (or the distance of a resulting effective charge) from the ion's original position is only $l<\mathrm{a}$, since structural changes have modified the local environment. In this sense, each data point in Fig. 8 indicates the decay of a given local structure that occurs during the process of charge relaxation.

The structural and dynamic development observed in molten CKN with increasing temperature leads from a decoupled ionic motion in a stable network to a coupled ionic motion in a fluid liquid. Figure 8 suggests that the $378 \mathrm{~K}$ transition marks the end of this transformation.

Regarding the shape of the structural decay in Fig.8, we note a surprising similarity to the decay of the order parameter in order-disorder transformations as, for instance, in $\mathrm{CuZn}$ and $\mathrm{Cu}_{3} \mathrm{Au}$. However, static equilibrium properties are considered in those cases, while time-dependent processes play an essential rôle in molten CKN. Nevertheless, the thermodynamic background will, in a broader sense, be similar, being based on the interplay of the energetic and entropic components in the Gibbs free energy. 
Besides its structural relevance, the $378 \mathrm{~K}$ transition has also considerable bearing on the ion dynamics. This is best expressed in terms of a function, $g(t)$, which was introduced in the MIGRATION concept to describe the decay of mismatch created by an elementary displacement of a mobile ion [26-28]. Being defined as $\mathrm{g}(\mathrm{t})=1-\ln \mathrm{W}(\mathrm{t}) / \ln \mathrm{W}(\infty)$, the mismatch function decays from $\mathrm{g}(0)=1$ to $\mathrm{g}(\infty)=0$.

Figure 9 is a log-log plot of six isotherms of $g(t)$, the temperatures being the same as those in Fig. 5 , with the same colour coding. The same functions $\mathrm{W}(\mathrm{t})$ have been used to derive the model spectra of Fig. 5 and the corresponding mismatch functions of Fig. 9.

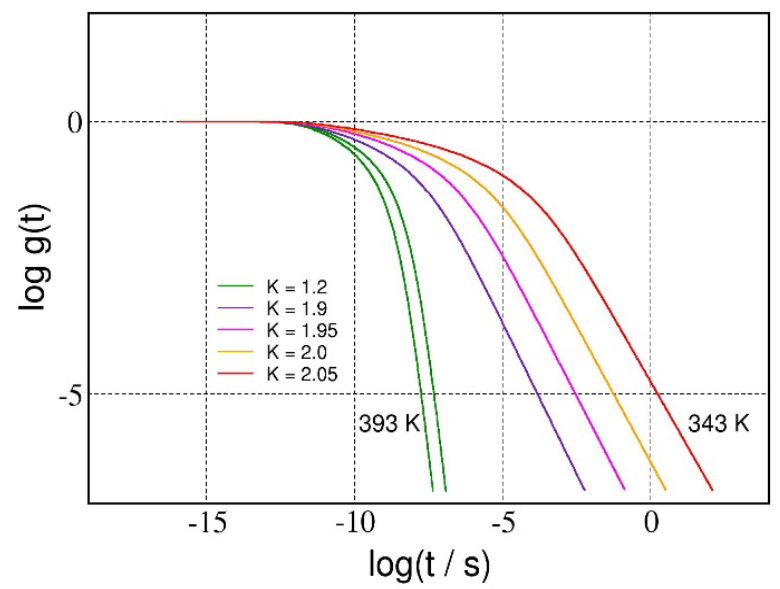

Fig. 9. Log-log plot of six isotherms of the time-dependent mismatch function for molten $C K N, g(t)$, corresponding to the six model spectra of Fig. 5 and derived from the same functions $W(t)$. Note the sudden increase of the long-time rate of decay between the $373 \mathrm{~K}$ and $383 \mathrm{~K}$ isotherms.

Writing Eq. (3) in terms of $\mathrm{g}(\mathrm{t})$, the long-time limiting behaviour of this function is found to follow a power law:

$$
\mathrm{g}(\mathrm{t}) \propto \mathrm{t}^{-1 /(\mathrm{K}-1)} \text { at long times. }
$$

The value of the shape parameter $K$ thus determines the rate of the final decay of $g(t)$. Therefore, the step displayed by $\mathrm{K}(\mathrm{x})$ at the $378 \mathrm{~K}$ transition corresponds to a sudden increase in the long-time decay rate of $\mathrm{g}(\mathrm{t})$, seen in Fig. 9 between the $373 \mathrm{~K}$ and $383 \mathrm{~K}$ isotherms. This feature reflects an abrupt increase in the facility with which an ionic neighbourhood, under the influence of the mismatch created by an elementary displacement of a 'central' ion, is able to rearrange and adjust positions, thus reducing and finally eliminating any memory of that displacement. This facility, acquired at 378 $\mathrm{K}$ and persisting at higher temperatures, includes an increased freedom of the nitrate ions [8] and is clearly due to the loss of the steric restrictions [10] imposed at lower temperatures by the existence of an intermediate range order.

Finally, in accordance with views presented in Refs. 8 and 10, we now also consider the rotational movements of the nitrate ions, which we regard as important for the short-time ion dynamics in CKN, both below and above the $378 \mathrm{~K}$ transition.

At low temperatures, where decoupled ionic motion prevails, the elementary displacements of the mobile potassium ions rely on a concerted rotational motion of neighbouring nitrate ions that belong to the long-lived network structure. At and above the $378 \mathrm{~K}$ transition, however, the ion dynamics are coupled, which means that now ions of different species perform their elementary displacements in a concerted fashion. Again, rotational flexibility of the nitrate ions is a precondition for these processes, enabling anions and cations to pass by each other easily. 


\section{Elastic Forces, Ionic Transport and Underlying Simplicity}

Essential complementary information on the long- and short-time dynamics of molten CKN, in excess of what has been found already in Section 3, is provided in this Section, on the basis of the 'master plot' of Fig. 10. As will be outlined, we are thus led to a new understanding of the energetics of the elementary displacements, where the action of elastic forces turns out to be the key aspect.

We refer now to the so-called activation moduli $[18,19,21]$, based in the case of CKN on the variable-pressure, variable-temperature (VPVT) studies of Angell, Pollard and Strauss [17], and of Williams and Angell [20], and on the temperature- and pressure-dependent conductivity relaxation times published more recently by Wojnarowska, Ngai and Paluch [22].

In the linear 'master plot' of activation energy, $E_{D C}$, versus activation volume, $V_{D C}$, constructed from the aforementioned data $[18,21,22,29], E_{D C}$ and $V_{D C}$ are the temperature-dependent activation energies and volumes for DC conductivity. In Fig. 10, the set of data points in the lower left of the figure has been taken at temperatures above the $378 \mathrm{~K}$ transition $[18,19,29]$, while the one in the upper right has been obtained immediately above $\mathrm{T}_{\mathrm{g}}$. In the latter case, the values for $\mathrm{E}_{\mathrm{DC}}$ and $\mathrm{V}_{\mathrm{DC}}$ have been read from the plots of $\log _{10}(\tau / \mathrm{s})$ versus temperature and pressure as published in Ref. 22 .

The slope of the straight line in Fig. 10, which passes close to or through the origin and connects the data points, is 5.6 GPa. Therefore, the activation modulus for DC conductivity,

$$
M_{\sigma}=\frac{E_{D C}(T)}{V_{D C}(T)}
$$

is found to be approximately 5.6 GPa in molten $\mathrm{CKN}$.

To assess the remarkable result of Fig. 10 within the framework of this paper, let us reconsider Fig. 1. At each temperature, activation energies can be read from that figure not only for the DC conductivity, but also for its HF counterpart. Now, again at each temperature, the corresponding DC activation volumes can be taken from Fig. 10, while the respective HF activation volumes are still missing. Fortunately, however, the MIGRATION concept formalism provides a means to determine this temperature-dependent quantity, $\mathrm{V}_{\mathrm{HF}}$. The argument, see Appendix 1, is based on the identity, $\sigma_{\mathrm{HF}}=\sigma_{\mathrm{DC}} \cdot \exp \mathrm{B}$, and yields the result that, at any given temperature, the same factor, $\mathrm{f}(\mathrm{T})$, will transform $\mathrm{E}_{\mathrm{DC}}(\mathrm{T})$ into $\mathrm{E}_{\mathrm{HF}}(\mathrm{T})$ and $\mathrm{V}_{\mathrm{DC}}(\mathrm{T})$ into $\mathrm{V}_{\mathrm{HF}}(\mathrm{T})$.

Building on this result, see Appendix 2, we can now derive the important identity,

$$
M_{\sigma}=\frac{E_{D C}(T)}{V_{D C}(T)}=\frac{E_{e d}}{V_{e d}},
$$

in which the temperature-dependent $\mathrm{DC}$ activation quantities, $\mathrm{E}_{\mathrm{DC}}(\mathrm{T})$ and $\mathrm{V}_{\mathrm{DC}}(\mathrm{T})$, are replaced by the constant activation quantities for elementary displacements, $\mathrm{E}_{\text {ed }}$ and $\mathrm{V}_{\text {ed. This }}$ equation plays a key rôle in our further discussion. Inserting $\mathrm{M}_{\sigma}=5.6 \mathrm{GPa}$ and $\mathrm{E}_{\mathrm{ed}}=26 \mathrm{~kJ} / \mathrm{mol}$ into Eq. (18), we obtain $\mathrm{V}_{\text {ed }} \approx 4.6 \mathrm{~cm}^{3} / \mathrm{mol}$ as an (average) activation volume for an elementary displacement in molten CKN. 


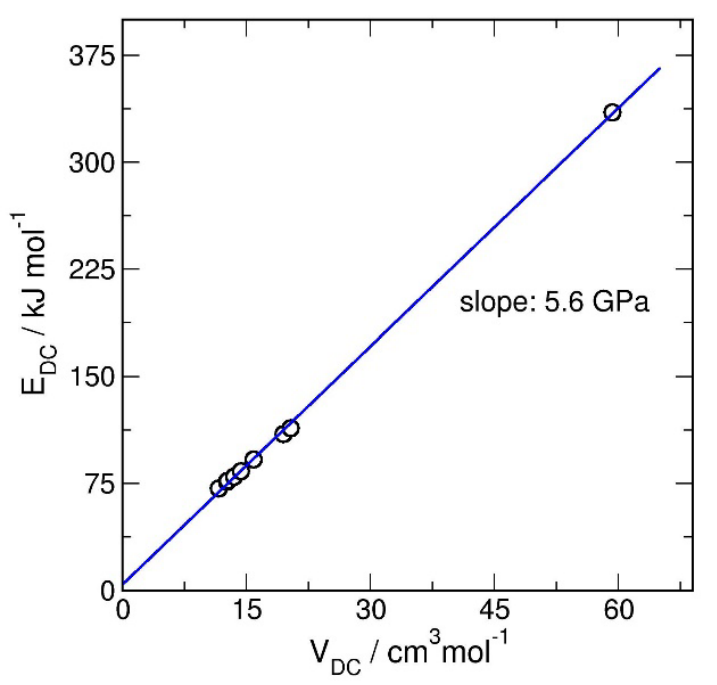

Fig. 10. 'Master plot' of activation energy, $E_{D C}$, versus activation volume, $V_{D C}$, for the $D C$ conductivity of molten CKN, according to data from Refs. 18, 19, 29 (high temperatures) and Ref. 22 (immediately above $\mathrm{T}_{\mathrm{g}}$ ). The slope of the straight line is $5.6 \mathrm{GPa}$.

Interestingly, $\mathrm{M}_{\sigma}$ is not the only activation modulus in CKN that has a value of about 5.6 GPa. The other one is $\mathrm{M}_{\mathrm{S}}$, the activation modulus for structural relaxation. For determining $\mathrm{M}_{\mathrm{S}}$, the pressure dependence of the glass transition temperature, $\mathrm{dT}_{\mathrm{g}} / \mathrm{dp}[19,21]$, is considered, as measured in the DSC experiments of Williams and Angell, under a constant heating rate [20]. In the process, the viscosity is assumed to remain at a constant value, $\eta_{\mathrm{g}}$, while $\mathrm{p}$ and $\mathrm{T}_{\mathrm{g}}$ are variable. Therefore, the total differential, $\mathrm{d} \eta_{\mathrm{g}}\left(\mathrm{p}, \mathrm{T}_{\mathrm{g}}\right)$, must vanish, providing an expression for $\mathrm{dT} \mathrm{T}_{\mathrm{g}} / \mathrm{dp}$ in terms of the activation quantities for structural relaxation, $E_{S}$ and $V_{S}[19,21]$. The result thus obtained is

$$
\mathrm{M}_{\mathrm{S}}=\frac{\mathrm{E}_{\mathrm{S}}}{\mathrm{V}_{\mathrm{S}}}=\frac{\mathrm{T}_{\mathrm{g}}}{\mathrm{dT} \mathrm{T}_{\mathrm{g}} / \mathrm{dp}}
$$

Insertion of $\mathrm{T}_{\mathrm{g}} \approx 333 \mathrm{~K}$ and $\mathrm{dT}_{\mathrm{g}} / \mathrm{dp} \approx 58 \mathrm{~K} / \mathrm{GPa}$ from Ref. 20 yields $\mathrm{M}_{\mathrm{S}} \approx 5.7 \mathrm{GPa}$.

Thus the two moduli, $\mathrm{M}_{\sigma}$ and $\mathrm{M}_{\mathrm{S}}$, are found to be (almost) identical, effectively linking together differing patterns of CKN behaviour occurring across the entire range of temperatures encountered in the present paper. In our further treatment, however, we focus attention on mobile charges, thus taking advantage of the existing information on their sub-picosecond dynamics.

It emerges now that a simple explanation for the value of $\mathrm{M}_{\sigma}$ may be contained in the Brillouin scattering data of Torell and Aronsson [38]. They reported values of transverse sound velocities measured at $6 \mathrm{GHz}$, and hence obtained shear moduli as a function of temperature in both molten and glassy CKN. While their values of the $6 \mathrm{GHz}$ shear modulus in the melt increased steadily with decreasing temperature (see also similar results for fragile melts published by Torchinsky et al. [39]) the shear modulus in the glass remained constant at a value of $\mathrm{G}$ (glass) $\approx 5.2 \mathrm{GPa}$.

Since CKN behaves as an elastic solid in the glassy state - both at short times and even at long times measured in hundreds of seconds - we propose that the value obtained at $6 \mathrm{GHz}$ could be accepted as the HF shear modulus of the glass, and write $\mathrm{G}_{\infty}$ (glass) $=5.2 \mathrm{GPa}$. In view of the very similar value of $5.6 \mathrm{GPa}$, which we have obtained for $\mathrm{M}_{\sigma}$, we are led now to suggest that the behaviour of molten $\mathrm{CKN}$ follows the very simple equation:

$$
\mathrm{E}_{\mathrm{DC}}(\mathrm{T})=\mathrm{G}_{\infty}(\text { glass }) \cdot \mathrm{V}_{\mathrm{DC}}(\mathrm{T})
$$

The virtue of Eq. (20) lies in relating quantities to each other that are all experimentally accessible. It should not be confused with an apparently similar equation proposed by Dyre et al. [40], which was based on their shoving model $[40,39]$ and contained a variable high-frequency shear modulus in combination with a constant critical volume, $\mathrm{V}_{\mathrm{C}}$. 
Because of Eq. (18), Eq. (20) can now be rewritten as $\mathrm{E}_{\text {ed }}=\mathrm{G}_{\infty}($ glass $) \cdot \mathrm{V}_{\text {ed }}$. Note that both $\mathrm{E}_{\text {ed }}$ and $\mathrm{V}_{\text {ed }}$ are independent of temperature. The observed increases in $E_{D C}$ and $V_{D C}$, which are seen with decreasing temperature, arise in molten CKN partly from the disappearance of target sites and hence from the reduction in the numbers of mobile ions, see Fig. 7, and to an even larger extent from the increased conductivity dispersion, see Fig. 5. In effect, it is these many-particle effects that lead to the well-known fragility of CKN.

In Section 3 we have shown that the same activation energy, Eed, applies for elementary displacements in the melt and in the glass. Now we see that the same HF shear modulus, $\mathrm{G}_{\infty}$, seems to be valid in the glass and in the melt, implying $\mathrm{G}_{\infty}($ melt $)=\mathrm{G}_{\infty}=\mathrm{G}_{\infty}$ (glass). Indeed, the equation

$$
\mathrm{E}_{\mathrm{ed}}=\mathrm{G}_{\infty} \cdot \mathrm{V}_{\mathrm{ed}}
$$

offers an understanding of the elementary displacement processes in terms of elastic forces, to be outlined below.

Here we need to emphasise that - by definition - the validity of the HF shear modulus, $\mathrm{G}_{\infty}$, is restricted to a time window that is short enough for the system (molten $\mathrm{CKN}$ in this case) to behave as an elastic solid. This is important in understanding the use of Eq. (21), where we are envisaging individual elementary displacements of individual ions in an otherwise arrested neighbourhood.

If, however, we allow for a time window in which a substantial fraction of the ions, or even all the ions, perform at least one elementary displacement, then this may be regarded as a (local) onset of fluidity, with the effect of reducing the value of the shear modulus. Comparing the inverse elementary displacement rates of the ions in molten CKN, see Eq. (11), with the time window defined by Torell and Aronsson's experimental frequency of $6 \mathrm{GHz}$ [38], we now realise that such a reduction must be expected to occur in CKN above $\mathrm{T}_{\mathrm{g}}$, the more so the higher the temperatures are. Therefore, the continuing decrease with increasing temperature observed in $\mathrm{G}($ melt) at $6 \mathrm{GHz}$ is not surprising, and it thus appears justified to interpret the constant factor in Eq. (21) as $\mathrm{G}_{\infty}=\mathrm{G}_{\infty}$ (melt).

To visualise the physical meaning of Eq. (21), we consider an elementary displacement of an individual ion, on its way from an initial position to a target site. In the process, let us suppose the ion is at some position $\xi$ between its starting point and the potential barrier. Then moving the ion forward by a further step, $\mathrm{d} \xi$, against the elastic force, $\mathrm{F}(\xi)$, will require an additional energy element, $\mathrm{dE}=$ $\mathrm{F}(\xi) \mathrm{d} \xi$. In a differential form, Eq. (21) may now be written as $\mathrm{dE}=\mathrm{F}(\xi) \mathrm{d} \xi=\mathrm{G}_{\infty} \mathrm{dV}$. Here $\mathrm{dV}$ denotes the extra volume element that needs to be made available for the ion by distorting its neighbourhood, while $\mathrm{G}_{\infty}$ represents the resistance exerted by the elastic structure. Eventually, $\mathrm{E}_{\text {ed }}$ and $\mathrm{V}_{\text {ed }}$ are obtained by integrating the energy and volume elements up to the point when the ion attains its barrier position, which results in Eq. (21).

With $E_{\text {ed }}, G_{\infty}$ and $V_{\text {ed }}$ all remaining unchanged in the entire temperature range of this study, the interpretation outlined above is indeed valid on either side of the glass transition. So an answer has now been found to the question posed by Scopigno et al. [32], asking if and how the behaviour of a fragile liquid is embedded within the properties of its glass. The answer is yes indeed and concerns the preservation of the way elastic forces act, which determine the sub-picosecond dynamics of the elementary displacements in both melt and glass.

In this sense, the behaviour of $\mathrm{CKN}$ is supposed to be paradigmatic both of fragile liquids and many ion-conducting glasses. We can therefore expect similar behaviour to that summarised in Eqs. (17) to (21) to be found in a wide range of materials of both practical and theoretical interest. Examples of AgI-containing and fast-ion conducting glasses where $\mathrm{M}_{\mathrm{S}}$ and $\mathrm{M}_{\sigma}$ have nearly identical values were given in Refs. 19 and 21. More recently, Wojnarowska et al. have found similar values for $\mathrm{M}_{\mathrm{S}}$ and $\mathrm{M}_{\sigma}$ for a proton-conducting polymer electrolyte based on acebutolol hydrochloride [41]. ${ }^{\$}$ There is clearly scope for further extensive and detailed studies of a much wider range of systems, very much along the lines set forth in this paper. 


\section{Conclusions}

In this study we have shown that the complexities of the ion dynamics in molten and glassy CKN can be traced back to an unexpected short-time simplicity. Here the essential first step has been to derive the high-frequency ionic conductivity, $\sigma_{\mathrm{HF}}$, which is caused by the elementary ionic displacements. This has been done in the framework of the MIGRATION concept.

When plotted versus inverse temperature, $\log \sigma_{\mathrm{HF}} \mathrm{T}$ has been found to be a curved line, see Figs. 1 and 7, which could be explained as arising from two kinds of processes. In the first, see Eqs. (12) and (13), new 'target sites' are created, while the other, see Eq. (11), is about the elementary displacements themselves. The values of the two respective activation energies, $\mathrm{E}_{\mathrm{f}}$ and $\mathrm{E}_{\mathrm{ed}}$, appear to be constant in the entire molten-salt temperature range, with $E_{\text {ed }}$ even remaining unchanged across the glass transition.

In a further step, we have shown how a comparison of the temperature-dependent HF and DC conductivities, see again Fig. 1, yields new insights into the decay of network structures above $\mathrm{T}_{\mathrm{g}}$. This decay becomes faster with increasing temperature not only on an absolute time scale, but also on the time scale of multi-particle relaxation. On the latter scale, intermediate range order is found to break down at the $378 \mathrm{~K}$ transition, thus minimising steric restrictions to ionic rearrangements.

Besides the activation energies, $\mathrm{E}_{\mathrm{DC}}(\mathrm{T})$ and $\mathrm{E}_{\mathrm{ed}}$, the corresponding activation volumes, $\mathrm{V}_{\mathrm{DC}}(\mathrm{T})$ and $\mathrm{V}_{\text {ed }}$, have also been considered. Starting out from the remarkable experimental finding that the ratio, $\mathrm{E}_{\mathrm{DC}}(\mathrm{T}) / \mathrm{V}_{\mathrm{DC}}(\mathrm{T})$, is constant over the entire molten-salt temperature range, we have now shown that this result can be traced back to the identity, $\mathrm{E}_{\mathrm{DC}}(\mathrm{T}) / \mathrm{V}_{\mathrm{DC}}(\mathrm{T})=\mathrm{E}_{\mathrm{ed}} / \mathrm{V}_{\text {ed. }}$. Finally, the suggestion that this ratio may be identified with the high-frequency shear modulus, $\mathrm{G}_{\infty}$, opens up wider possibilities for explaining the energetics of elementary ionic displacements in disordered systems through the action of elastic forces.

\section{Appendix}

\section{Part 1:}

It is shown that for molten $\mathrm{CKN}$, at any given temperature, the same factor, $\mathrm{f}$, may be used to transform $E_{D C}$ into $E_{H F}$ and $V_{D C}$ into $V_{H F}$. Therefore, the ratios $E_{D C}(T) / V_{D C}(T)$ and $E_{H F}(T) / V_{H F}(T)$ are identical.

Expressing the dependences on temperature and pressure of $\sigma_{\mathrm{DC}} \mathrm{T}$ and $\sigma_{\mathrm{HF}} \mathrm{T}$ by activation enthalpies, $\mathrm{H}_{\mathrm{DC}}=\mathrm{E}_{\mathrm{DC}}+\mathrm{p} \mathrm{V}_{\mathrm{DC}}$ and $\mathrm{H}_{\mathrm{HF}}=\mathrm{E}_{\mathrm{HF}}+\mathrm{p} \mathrm{V}_{\mathrm{HF}}$, the relation $\mathrm{H}_{\mathrm{HF}}=\mathrm{H}_{\mathrm{DC}}-\mathrm{B} \cdot \mathrm{k}_{\mathrm{B}} \mathrm{T}$ is obtained from $\sigma_{H F} T=\sigma_{D C} T \cdot \operatorname{exp~B}$. With the abbreviation $f=1-B \cdot k_{B} T / H_{D C}$, this implies $H_{H F}=H_{D C} \cdot f$ and hence $E_{H F}=E_{D C} \cdot f$ and $V_{H F}=V_{D C} \cdot f$ as well. The activation modulus, $M_{\sigma}$, may therefore be written as

$$
M_{\sigma}=\frac{E_{D C}(T)}{V_{D C}(T)}=\frac{E_{H F}(T)}{V_{H F}(T)} .
$$

This argument will not be affected by a possible pressure dependence of the parameter B.

\footnotetext{
$\$$ In most (and we suggest in all) fragile melts the values for $\mathrm{M}_{\mathrm{S}}$ and $\mathrm{M}_{\sigma}$ are found similar, and hence our treatment outlined in Section 5 is applicable. To give just two examples of a very different pattern of behaviour, Bagdassarov et al. [42] have earlier reported a negative dependence of $\mathrm{T}_{\mathrm{g}}$ on pressure in haplogranitic silicate glasses of geological interest, while Mori et al. [43] have reported that the viscosities of similar aluminosilicate melts held at $2000 \mathrm{~K}$ actually decrease with increasing pressure. These examples of what might be termed 'water-like' behaviour have their origins in the collapse of tetrahedral network structures under applied pressure. Paradoxically, this structural vulnerability seems to be a particular feature of 'strong' glass-forming melts.
} 


\section{Part 2:}

Here we show that the ratios $\mathrm{E}_{\mathrm{HF}}(\mathrm{T}) / \mathrm{V}_{\mathrm{HF}}(\mathrm{T})$ and $\mathrm{E}_{\text {ed }} / \mathrm{V}_{\text {ed }}$ are identical.

Inspection of Fig. 7 reveals the reason why $\mathrm{E}_{\mathrm{HF}}$ is temperature-dependent. This is due to the fact that the number density function, $\mathrm{n}$, in contrast to the function $\mathrm{n}_{\mathrm{A}}$, is not Arrhenius, but characterised by a temperature-dependent activation energy, $\mathrm{E}_{\mathrm{n}}(\mathrm{T})$. Therefore, the HF activation quantities must be written as $E_{H F}(T)=E_{e d}+E_{n}(T)$ and $V_{H F}(T)=V_{\text {ed }}+V_{n}(T)$. Using Eq. (13) in order to derive $E_{n}(T)$ and $V_{n}(T)$ in terms of the activation energy and volume for the formation of mobile charges, denoted by $E_{f}$ and $V_{f}$, respectively, cf. Eq. (12), we find that both $E_{n}(T)$ and $V_{n}(T)$ differ from the latter quantities by the same temperature-dependent factor, $\mathrm{n}(\mathrm{T}) / \mathrm{n}_{\mathrm{A}}(\mathrm{T})$, here abbreviated as $\mathrm{C}(\mathrm{T})$. We may thus write $\mathrm{E}_{\mathrm{HF}}(\mathrm{T}) / \mathrm{V}_{\mathrm{HF}}(\mathrm{T})=\left(\mathrm{E}_{\text {ed }}+\mathrm{C}(\mathrm{T}) \cdot \mathrm{E}_{\mathrm{f}}\right) /\left(\mathrm{V}_{\text {ed }}+\mathrm{C}(\mathrm{T}) \cdot \mathrm{V}_{\mathrm{f}}\right)$. As the factor $\mathrm{C}(\mathrm{T})$ varies with temperature considerably, see Fig. 7, this equation can only be fulfilled, if the ratios $\mathrm{E}_{\mathrm{HF}}(\mathrm{T}) / \mathrm{V}_{\mathrm{HF}}(\mathrm{T})$, $\mathrm{E}_{\text {ed }} / \mathrm{V}_{\text {ed }}$ and $\mathrm{E}_{\mathrm{f}} / \mathrm{V}_{\mathrm{f}}$ are all identical.

In the expression for $M_{\sigma}$, we may therefore replace $E_{H F}(T)$ and $V_{H F}(T)$ by the temperatureindependent $\mathrm{HF}$ activation quantities, $\mathrm{E}_{\text {ed }}$ and $\mathrm{V}_{\text {ed }}$ :

$$
M_{\sigma}=\frac{E_{D C}(T)}{V_{D C}(T)}=\frac{E_{H F}(T)}{V_{H F}(T)}=\frac{E_{e d}}{V_{e d}} .
$$

\section{Acknowledgements}

The conductivity spectra here reanalysed were originally measured by P. Singh as part of his doctoral work at University of Muenster and have been already published. This present paper marks the culmination of an extended collaboration, which owes much to the generosity of the Research Award received several years ago from the Alexander von Humboldt Foundation that MDI is pleased to acknowledge. RDB gratefully acknowledges funding provided via an European Union Seventh Framework Programme (FP7 2007-2013) under grant agreement $n^{\circ} 291823$ Marie Curie FP7PEOPLE-2011-COFUND (The new International Fellowship Mobility Programme for Experienced Researchers in Croatia - NEWFELPRO) project 'MODELMATSIGMA' under grant agreement $\mathrm{n}^{\circ}$ [80].

\section{References}

[1] C.A. Angell, Free volume model for transport in fused salts: electrical conductance in glassforming nitrate melts, J. Phys. Chem. 68 (1964) 1917-1929.

[2] H. Vogel, The law of the relation between viscosity of liquids and the temperature, Phys. Z. 22 (1921) 645-646.

[3] G. Tammann, W. Hesse, Die Abhängigkeit der Viskosität von der Temperatur bei unterkühlten Flüssigkeiten, Z. Anorg. Allg. Chem. 156 (1926) 245-257.

[4] G.S. Fulcher, Analysis of recent measurements of the viscosity of glasses, J. Am. Ceram. Soc. 8 (1925) 339-355.

[5] C.A. Angell, Oxide glasses in the light of the "ideal glass" concept: I, ideal and nonideal transitions, and departure from ideality, J. Am. Ceram. Soc. 51 (1968) 117-124.

[6] R. Bose, R. Weiler, P.B. Macedo, Temperature dependence of conductance of a vitreous $\mathrm{KNO}_{3}$ $-\mathrm{Ca}\left(\mathrm{NO}_{3}\right)_{2}$ mixture, Phys. Chem. Glasses 11 (1970) 117-\&.

[7] F.S. Howell, R.A. Bose, P.B. Macedo, C.T. Moynihan, Electrical relaxation in a glass-forming molten salt, J. Phys. Chem. 78 (1974) 639-648.

[8] M.C.C. Ribeiro, T. Scopigno, G. Ruocco, Computer simulation study of thermodynamic scaling of dynamics of $2 \mathrm{Ca}\left(\mathrm{NO}_{3}\right)_{2} \cdot 3 \mathrm{KNO}_{3}$, J. Chem. Phys. 135 (2011) 164510-(1-9).

[9] Z. Akdeniz, M.P. Tosi, Microstructure of mixed-nitrate melts and glasses, Phys. \& Chem. Liquids 44 (2006) 361-365. 
[10]C. Tengroth, J. Swenson, A. Isopo, L. Börjesson, Structure of $\mathrm{Ca}_{0.4} \mathrm{~K}_{0.6}\left(\mathrm{NO}_{3}\right)_{1.4}$ from the glass to the liquid state, Phys. Rev. B 64 (2001) 224207-(1-9) .

[11]C.A. Angell in: "Relaxations in Complex Systems”, K.L. Ngai and G.B. Wright(Eds), GPO, Washington DC, U.S.A., 1985, pp. 3-16.

[12]V.N. Novikov, A.P. Sokolov, Poisson's ratio and the fragility of glass-forming liquids, Nature 431 (2004) 961-963.

[13] W. Götze, L. Sjögren, Relaxation processes in supercooled liquids, Rep. Prog. Phys. 55 (1992) 241-376.

[14] G. Li, W.M. Du, X.K. Chen, H.Z. Cummins, N.J. Tao, Testing mode-coupling predictions for $\alpha$ and $\beta$ relaxation in $\mathrm{Ca}_{0.4} \mathrm{~K}_{0.6}\left(\mathrm{NO}_{3}\right)_{1.4}$ near the liquid-glass transition by light scattering, Phys. Rev. A 45 (1992) 3867-3879.

[15]F. Mezei, M. Russina, Intermediate range order dynamics near the glass transition, J. Phys. Condensed Matter 11(1999) A 341-A354.

[16] K.L. Ngai, J. Habasaki, An alternative explanation of the change in T-dependence of the effective Debye-Waller factor at $\mathrm{T}_{\mathrm{c}}$ or $\mathrm{T}_{\mathrm{B}}$, J. Chem. Phys. 141(2014) 114502-(1-16).

[17]C.A. Angell, J.L. Pollard, W. Strauss, Transport in Molten Salts under Pressure. I. Glass-Forming Nitrate Melts, J. Chem. Phys. 50(1969) 2694-2705.

[18]M.D. Ingram, C. T. Imrie, Z. Stoeva, S.J. Pas, K. Funke, H.W. Chandler, Activation EnergyActivation Volume Master Plots for Ion Transport Behavior in Polymer Electrolytes and Supercooled Molten Salts, J. Phys. Chem. B Letters 109 (2005) 16567-16570.

[19]M.D. Ingram, C.T. Imrie, J. Ledru, J.M. Hutchinson, Unified approach to ion transport and structural relaxation in amorphous polymers and glasses, J. Phys. Chem. B 112 (2008) 859-866.

[20]E. Williams, C.A. Angell, Pressure dependence of the glass transition temperature in ionic liquids and solutions. Evidence against free volume theories, J. Phys. Chem. 81 (1977) 232-237.

[21] M.D. Ingram, C.T. Imrie, New insights from variable-temperature and variable-pressure studies into coupling and decoupling processes for ion transport in polymer electrolytes and glasses, Solid State Ionics 196 (2011) 9.

[22]Z. Wojnarowska, K.L. Ngai, M. Paluch, Invariance of conductivity relaxation under pressure and temperature variations at constant conductivity relaxation time in $0.4 \mathrm{Ca}\left(\mathrm{NO}_{3}\right)_{2}-0.6 \mathrm{KNO}_{3}, \mathrm{Phys}$. Rev. E 90 (2014) 062315-(1-5).

[23]P. Lunkenheimer, A. Pimenov, A. Loidl, Fast dynamics in CKN and CRN investigated by dielectric spectroscopy, Phys. Rev. Letters 78 (1997) 2995-2998.

[24] J. C. Dyre, Aging of CKN: Modulus versus conductivity analysis. Phys. Rev. Letters 110 (2013) 245901-(1-4).

[25]P. Singh, R.D. Banhatti, K. Funke, Correlation between viscosity and ion dynamics in a fragile ionic melt. Phys. Chem. Glasses 46 (2005) 241-244.

[26]K. Funke, R.D. Banhatti, Modelling frequency-dependent conductivities and permittivities in the framework of the MIGRATION concept, Solid State Ionics 169 (2004) 1-8.

[27]K. Funke, R.D. Banhatti, Ionic motion in materials with disordered structures. Solid State Ionics 177 (2006) 1551-1557.

[28]K. Funke, R. D. Banhatti, D. M. Laughman, L.G. Badr, M. Mutke, A. Šantić, W. Wrobel, E.M. Fellberg, C. Biermann, First and second universalities: Expeditions towards and beyond. Z. Phys. Chem. 224 (2010) 1891-1950. 
[29] K. Funke, M.D. Ingram, R.D. Banhatti, P. Singh, S.J. Pas, Ionic conductivity of a fragile glassforming molten salt: Modelling its dependence on frequency, temperature, and pressure, $\mathrm{Z}$. Metallkunde 95 (2004) 921-927.

[30]P. Singh, Fragility and the Coupled to Decoupled Transition in Supercooled Molten Calcium Potassium Nitrate Studied by Broad-Band Conductivity Spectroscopy, Ph.D. Thesis, University of Münster, Germany, 2005.

[31]R. Kubo, Statistical-mechanical theory of irreversible processes. I. General theory and simple applications to magnetic and conduction problems, J. Phys. Soc. Jpn. 12 (1957) 570-586.

[32]T. Scopigno, G. Ruocco, F. Sette, G. Monaco, Is the fragility of a liquid embedded in the properties of its glass?, Science 302 (2003) 849-852.

[33] S. Summerfield, Universal low-frequency behaviour in the ac hopping conductivity of disordered systems, Phil. Mag. B, 52 (1985) 9-22.

[34]A. Šantić, W. Wrobel, M. Mutke, R.D. Banhatti, K. Funke, Frequency-dependent fluidity and conductivity of an ionic liquid, Phys. Chem. Chem. Phys. 11 (2009) 5930-5934.

[35]K. Funke, R.D. Banhatti, P. Grabowski, J. Nowinski, W. Wrobel, R. Dinnebier, O. Magdysyuk, Low-temperature $\alpha$-AgI confined in glass: Structure and dynamics, Solid State Ionics 271 (2015) 29.

[36]K.L. Ngai, R.W. Rendell, C. Leon, The crossover from the near constant loss to ion hopping ac conductivity in ionic conductors: the crossover times, J. Non-Cryst. Solids 307 (2001) 1039-1049.

[37]K. Funke, R.D. Banhatti, P. Singh, Conductivity dispersion in supercooled calcium potassium nitrate: caged ionic motion viewed as part of standard behaviour, Phys. Chem. Chem. Phys. 9 (2007) $5582-5590$.

[38]L.M. Torell, R. Aronsson, Brillouin scattering study of elastic properties in a glass forming $\mathrm{KNO}_{3}-\mathrm{Ca}\left(\mathrm{NO}_{3}\right)_{2}$ mixture, J. Chem. Phys. 78 (1983) 1121-1125.

[39]D.H. Torchinsky, J.A. Johnson, K.A. Nelson, A direct test of the correlation between elastic parameters and fragility of ten glass formers and their relationship to elastic models of the glass transition, J. Chem. Phys. 130 (2009) 064502-(1-11).

[40]J.C. Dyre, T. Christensen and N.B. Olsen, Elastic models for the non-Arrhenius viscosity of glass-forming liquids, J. Non-Cryst. Solids 352 (2006) 4635-4642.

[41]Z. Wojnarowska, M. Rams-Baron, J. Knapik-Kowalczuk, A. Połatyńska, M. Pochylski, J. Gapinski, A. Patkowski, P. Wlodarczyk, M. Paluch, Experimental evidence of high pressure decoupling between charge transport and structural dynamics in a protic ionic glass-former, Scientific Reports 7 (2017) 7084-(1-8).

[42] N.S. Bagdassarov, J. Maumus, B. Poe, A.B. Slutskiy, V.K. Bulatov, Pressure dependence of $\mathrm{T}_{\mathrm{g}}$ in silicate glasses from electrical impedance measurements, Phys. Chem. Glasses 45 (2004) 197-214.

[43] S. Mori, E. Ohtani, A. Suzuki, Viscosity of the albite melt to $7 \mathrm{GPa}$ at $2000 \mathrm{~K}$, Earth and Planetary Science Letters 175 (2000) 87-92. 